\title{
THE USE OF POLYETHYLENE TEREPHTHALATE WASTE FOR MODIFYING ASPHALT CONCRETE USING THE MARSHALL TEST
}

Olumide Moses Ogundipe ${ }^{1 *}$

\section{Abstract}

This study considers the use of polyethylene terephthalate (PET) waste for modifying asphalt concrete. In the study, the optimum bitumen content of asphalt concrete was replaced with 4\%, 6\%, $8 \%, 10 \%, 12 \%, 14 \%$ and $16 \%$ of PET waste; the Marshall test was conducted on the samples. A comparison of the unmodified and PET-modified asphalt concrete showed that the stability of the modified asphalt concrete was reduced. The maximum stability for the PET waste-modified asphalt concrete was recorded at a content of $12 \%$ PET waste. This gives about a $20.4 \%$ reduction in stability. The study reveals that the addition of PET waste to the asphalt concrete causes a reduction in the flow value except with the addition of $14 \%$ and $16 \%$ waste. This implies that the introduction of PET waste could improve the permanent deformation resistance of asphalt, although there is concern about a reduction in fatigue resistance.
Address

1 Dept. of Civil Engineering, Ekiti State University, Ado-Ekiti, Nigeria

* Corresponding author: momide2002@yahoo.com

\section{Key words}

- Asphalt concrete

- Waste

- Polyethylene terephthalate, Marshall test,

- Stability, flow.

\section{INTRODUCTION}

In Nigeria and many other countries, the safe disposal of solid waste is of great concern to their environmental protection agencies. The random disposal of worn-out automobile tyres and plastics is considered to be one of the major causes of damage to our ecosystem that result in alarming health problems for all types of life (Sulyman et al., 2014). Also, plastics have been habitually mixed with our municipal solid wastes and sometimes disposed of in soil; in terms of their chemical characteristics as represented by their chemical bonds, they are very durable and non-biodegradable; they therefore require very effective management worldwide (Sulyman et al., 2014). Lytle (2011) reported global plastic production of an unprecedented record of 299 million metric tons in 2013. He stated that that production represents a $498 \%$ increase compared to the 50 million metric tons produced in 1976. Different types of plastics include low density polyethylene, high density polyethylene, polyvinylchloride, polystyrene, polypropylene, polyethylene terephthalate (PET), etc. According to Lewandowski (1994), the main reasons to modify asphalts with plastics are to obtain softer blends at low service temperatures and reduc- ing cracking; obtain stiffer blends at high temperatures and reduce rutting; reduce viscosity; increase the stability and strength of mixtures; improve resistance to abrasion and resistance to the fatigue of blends, oxidation and aging; and reduce the structural thickness and life costs of pavements. The focus of this study is polyethylene terephthalate (PET) waste in the form of plastic bottles used for packaging potable water. According to Jabarin (1996), PET is a transparent polymer with good mechanical properties and dimensional stability under variable loads. Also, it has good gas barrier properties and good chemical resistance.

Plastics contribute significantly to the generation of solid waste. This is because it is used for domestic, industrial and agricultural purposes including bags, water containers, cooking utensils, cutlery, pipes, ceilings, electric cables, etc. A disadvantage of the use of plastic is that it is non-biodegradable. Therefore, it constitutes an environmental hazard. As urbanization is making it more difficult to acquire suitable sites for landfills, it is important that the focus be shifted towards the re-use and recycling of plastic. These activities are being undertaken in developed countries. It is important that developing countries like Nigeria embrace the recycling of plastic 
in concrete. Moreover, studies have shown that the introduction of polymers can improve the properties of asphalt concrete as enumerated in this section. Abdul Rahman and Omardin (2016) evaluated the optimum bitumen content and the characteristic of recycled Polyethylene Terephthalate (PET) as a partial replacement for fine aggregates in asphalt mixtures for road pavements by determining their rutting, fatigue, and stiffness properties. The results showed the highest stiffness modulus value for $0 \%$ PET-modified asphalt was recorded at $5.5 \%$ bitumen content. They concluded that all PET-modified asphalt appeared to be capable of resisting the rutting of road pavements, while $5 \%$ and $15 \%$ PET-modified asphalt showed more resistance to fatigue than unmodified asphalt. Sulyman et al (2016) reviewed the use of PET in civil engineering projects such as road pavements, cement and concrete. They concluded that plastic waste (PET) may be applied to modifications of road pavement asphalt and building concrete. They stated that the use of PET waste for the modification of asphalt, cement and concrete improved their properties and reduced the use of new polymeric materials, which has a significant effect on environmental pollution (e.g., the emission of carbon dioxide, waste disposal problems, etc.).

Ahmadinia et al. (2011) stated that one way to reduce the cost of road construction and rendering it more practical was by using inexpensive polymers, i.e., waste polymers. They carried out research to determine the effect on the engineering properties of incorporating waste plastic bottles (polyethylene terephthalate (PET)) in a stone mastic asphalt (SMA) mixture using $0 \%, 2 \%, 4 \%, 6 \%, 8 \%$ and $10 \%$ PET; they found the appropriate amount of PET to be $6 \%$ according to the weight of the bitumen. The results showed that the addition of PET has a significant and positive effect on the properties of SMA and could promote the reuse of waste material in industry in an environmentally friendly and economical way. Abdul-Rahman and Abdul-Wahab (2013) studied the effects of using waste plastic containing $55-60 \%$ polyethylene terephthalate (PET) as a partial replacement for fine aggregates on the stiffness and permanent deformation of an asphalt wearing course. They used the PET to replace between 5 and $25 \%$ of the aggregate sizes ranging from $1.18 \mathrm{~mm}$ to $2.36 \mathrm{~mm}$. The results showed that the resilient modulus value of unmodified asphalt is greater than recycled PET modified asphalt, while the permanent deformation resistance of the modified asphalt improves; a $20 \%$ replacement gives the best performance.

Appiaha et al. (2017) examined the effect of blending waste thermoplastic polymers, namely, high density polyethylene (HDPE) and polypropylene (PP) in conventional AC-20 graded bitumen, in various plastic compositions as a means for the proper management of municipal solid waste (MSW), particularly plastics as a solution to the formation of potholes on roads due to excessive traffic and axle weight. In their study, the plastics were shredded and blended with the bitumen 'in-situ' with a shear mixer at a temperature range of $160{ }^{\circ} \mathrm{C}-170{ }^{\circ} \mathrm{C}$. They found that the properties of the unmodified bitumen were enhanced. They stated that polypropylene polymer had a profound effect on the bitumen's homogeneity and compatibility with a slight linear increment in the viscosity, softening, and penetration values versus the relatively high amount of changes for HDPE modified bitumen. They reported that the viscosity of the unmodified bitumen was improved with the addition of the polymers. Generally, their results showed that the penetration values decrease as the polymer-bitumen ratio increases, while the softening temperature generally increases as the polymer ratio increases. Awaeed et al. (2012) examined the use of polyethylene terephthalate (PET) to improve the properties of asphalt concrete. They used five different proportions $(2,4,6,8$ and $10 \%)$ as additives of the optimum bitumen content of $5 \%$ according to the weight of the aggregates. They heated the bitumen in an oven, and the PET was cut into small sizes using a shredding machine before being added to the bitumen. They were left in the oven for 45 minutes at $150{ }^{\circ} \mathrm{C}$. The aggregates and filler of each specimen were heated until they reached $160-170{ }^{\circ} \mathrm{C}$. They reported that the bulk density increases as the amount of PET increases. Also, the stability of the modified asphalt was higher than that of the unmodified asphalt, with the maximum stability value recorded at an $8 \%$ PET content.

Gawande et al. (2012) observed that the amount of plastic waste in India was greater due to increases in the population, urbanization, development activities, and changes in life styles, which led to widespread littering. Therefore, they decided to review the literature on the effective utilization of waste, which was becoming a serious problem due to its non-biodegradability. They concluded that the use of recycled plastic waste in pavement asphalt would represent a valuable outlet for the safe disposal of such materials and that it would help in substantially improving the Marshall stability, strength, fatigue life, and other desirable properties of a bituminous concrete mix, thereby resulting in an improved pavement performance with marginal savings in the use of bitumen. Moghaddam et al. (2013) investigated the effects of adding plastic to road pavements. They evaluated the Marshall properties as well as the specific gravity of an asphalt mixture containing different percentages of plastic. The results showed that the stability and flow values of an asphalt mixture increased by adding shredded waste plastic bottles to an asphalt mixture. They also found that the bulk specific gravity and stiffness of the mixtures increased by adding a smaller amount of the shredded plastic bottles; on the other hand, adding higher amounts of plastic resulted in a lower specific gravity and a stiffer mix.

Hassan et al. (2005) studied the use of $3 \mathrm{~mm}$ PET granule pellets as a partial fine aggregate replacement in an asphalt mixture with $60 / 70$ penetration grade bitumen and a maximum aggregate size of $12.5 \mathrm{~mm}$ using the Marshall test. The results showed that replacing $20 \%$ of the aggregates with PET was appropriate. Awwad and Shbeeb studied the prospects of using polyethylene to enhance the properties of an asphalt mixture using the Marshall test. They investigated both high density polyethylene (HDPE) and low density polyethylene (LDPE) with the aim of determining the better polymer for modifying an asphalt mixture. They considered two states (ground and not ground) and replaced the optimum bitumen content with $6,8,10,12$, 14,16 and $18 \%$ of the two polymers. The results indicated that the ground HDPE modifier provides better engineering properties than the LDPE. Also, it was determined that grinding the polyethylene provides better physical properties and that the optimum polyethylene content was $12 \%$ by weight of the bitumen content.

Rahman et al. (2013) investigated the use of polyethylene and polyvinylchloride (PVC) as additives to enhance asphalt mixture properties. The study focused on a test of the modified binder properties. They used a Marshall mix design to determine the optimum binder content and test the modified mixture properties. They found that the penetration, ductility, and solubility values of the modified asphalt mixture decreased when increasing the polyethylene and PVC modifier, while the softening point increased with an increase in the modifiers. They concluded that asphalt mixtures with a waste Polyethylene modifier of up to $10 \%$ and a waste PVC modifier of up to $7.5 \%$ can be used for flexible pavement construction in a warmer region from the standpoints of stability, stiffness, and void characteristics. Kotresh et al. (2016) investigated the optimal use of plastic waste in bitumen for road pavement construction. They added shredded plastic bottles in proportions ranging from $0 \%-10 \%$ to a bituminous concrete mix. They reported a maximum stability of $1963 \mathrm{~kg}$ and a $4.7 \mathrm{~mm}$ flow at $8 \%$. They stated that the maximum stability recorded when $8 \%$ shredded plastic bottles were added was lower than the conventional mix because the melting temperature of the plastic was too high, which made it difficult to get a properly blended plastic-bitumen mix. Shiva et. al. (2012) investigated the use of plastic waste in 
asphalt containing $60 / 70$ and $80 / 100$ bitumen using the Marshall mix design method. They introduced 2, 4, 6, 8, 10 and $12 \%$ plastic waste into an asphalt mix as a percentage of the optimum bitumen contents of the two mixtures. The results showed that the stability increased with an increasing plastic content. The optimum addition of the plastic was found to be $8 \%$. They reported that for a mixture containing $60 / 70$ bitumen, the flow increases when increasing the plastic, while the flow reduces for 80/100 bitumen.

Sabina et al (2009) used polythene waste to modify a bituminous mixture with a $60 / 70$ penetration grade bitumen. In their study, they reported that the Marshall stability and retained stability of the polythene-modified bituminous concrete using $8 \%$ and $15 \%$ polythene according to the weight of the bitumen were 1.21 and 1.18 times higher than that of a conventional mix. They found that the bituminous concrete with $15 \%$ polythene has a lower Marshall stability than the $8 \%$ polythene. Sui and Chen (2011) investigated the performance of polyethylene in an asphalt mixture. The polyethylene was added to and coated the hot aggregates before the bitumen was introduced into the mixtures. They observed that there is an improvement in stability at a high temperature and cracking at a low temperature; the polyethylene-modified mixture had better water resistance. Vasudevan et al (2010) worked on the performance of polymer-coated aggregates in flexible pavements and found that the polymer improves soundness, while it also reduces porosity and the absorption of water, thereby leading to improved pavement performance.

Generally, a review of the literature reveals that different forms of plastic have been used to modify bituminous mixtures and have been found to improve some of its properties. This study investigates the Marshall properties of typical asphalt concrete used in Nigeria, which has been modified with PET for road construction. It is aimed at encouraging road construction and management agencies to adopt the use of plastic waste in asphalt to reduce the concerns of waste management authorities about ensuring the safe disposal of such waste.

\section{MATERIALS AND METHODS}

\subsection{Materials}

The materials used for the study are $19 \mathrm{~mm}, 12.5 \mathrm{~mm}$, and 9.5 $\mathrm{mm}$ single-sized aggregates, quarry dust and river sand, bitumen (60/70 penetration grade), and plastic waste (PET). The PET consists of waste water bottles grouped as 1 for recycling purposes.

\subsection{Methods}

The aggregates used for the research were subjected to a mechanical sieve analysis to determine the particle size distribution, while the bitumen was subjected to a penetration test. The composition of the asphalt concrete mix composition was prepared to fall within the Federal Government of Nigeria's Specifications for Road and Bridges (FGN, 1997). The asphalt mixture was prepared as shown in Table 1 with $4 \%, 4.5 \%, 5.0 \%, 5.5 \%$ and $6 \%$ bitumen content according to the weight of the aggregates. The samples were subjected to the Marshall test to determine the optimum bitumen content. The optimum bitumen content was determined using the Asphalt Institute Procedure, i.e., the average of the bitumen contents that correspond to maximum stability, maximum density, and $4 \%$ air voids. Once the optimum bitumen content was determined, the modified asphalt concrete samples were prepared by replacing the optimum bitumen content with $4 \%, 6 \%, 8 \%, 10 \%, 12 \%, 14 \%$ and $16 \%$ PET according to the weight of the bitumen. The PET-modified asphalt concrete samples were subjected to the Marshall test to examine the effects of the modifier.
Table 1: Mix composition

\begin{tabular}{|c|c|}
\hline Size (mm) & Proportion of proposed mix (\%) \\
\hline $19 \mathrm{~mm}$ & 8.0 \\
\hline $12.5 \mathrm{~mm}$ & 22.0 \\
\hline $9.5 \mathrm{~mm}$ & 17.0 \\
\hline Quarry dust & 38.0 \\
\hline River sand & 15.0 \\
\hline Total (\%) & 100 \\
\hline
\end{tabular}

\subsection{Test Procedures}

\subsubsection{Mechanical sieve analysis}

The aggregate gradations were determined in accordance with BS EN 933-1:2012 (BSI, 2012).

\subsubsection{Penetration test}

The penetration test is a measure of the consistency of the bitumen expressed as the distance in tenths of a millimetre (decimilimeter) that a standard needle is allowed to penetrate vertically into a sample of the bitumen, under a specified load and loading time, at a fixed temperature of $25^{\circ} \mathrm{C}$ (Airey, 1997). The penetration test was carried out in accordance with BS EN 1426:2015 (BSI, 2015).

\subsubsection{Marshall test}

The samples (cores) for the Marshall test were prepared by blending the aggregates as shown in Table1. Then, $1200 \mathrm{~g}$ of the blended aggregates were weighed along with $4 \%$ bitumen according to the weight of the aggregates. The aggregates were heated to a temperature of $150^{\circ} \mathrm{C}$ before being mixed with the bitumen. A crater was formed in the aggregate, and the $60 / 70$ penetration grade bitumen heated to $150^{\circ} \mathrm{C}$ was added. The aggregates and the bitumen were mixed until all the aggregates were properly coated. Filter paper was placed in the bottom of a thoroughly cleaned mould and heated to $150^{\circ} \mathrm{C}$; the mixture placed in the mould was spread with a heated spatula around the perimeter. The collar was removed, and the surface of the mix was smoothed with a trowel to a slightly rounded shape. The temperature of the mixture immediately prior to compaction was maintained at $140^{\circ} \mathrm{C}$. The collar was replaced, and the mould assembly was placed on the compaction pedestal in the mould holder; the top of the specimen was then given 75 blows. The baseplate and the collar were removed; the sample was then inverted and the mould reassembled. The inverted face was also given 75 blows. After compaction, the base plate was removed, and the specimen was removed from the mould by means of a sample extractor and a suitable jack and frame arrangement. The specimen was placed on a smooth, flat surface and allowed to cool to room temperature. The process was repeated for the production of the samples with $4.5 \%, 5.0 \%, 5.5 \%$, and $6.0 \%$ bitumen according to the weight of the aggregates. The modified asphalt concrete samples were produced using the same process, but with the optimum bitumen content replaced with $4 \%, 6 \% 8 \%, 10 \%, 12 \%$, $14 \%$, and $16 \%$ PET according to the weight of the bitumen. The PET (plastic bottles) were shredded and melted in the oven before being mixed with the bitumen. The density of each sample was determined 


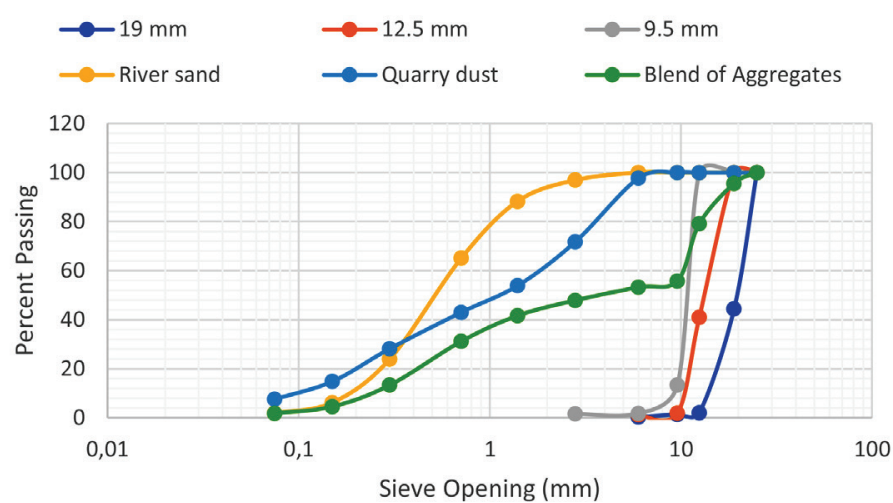

Fig. 1: The particle size distribution curves of the aggregates and mixture of aggregates for the asphalt concrete

by weighing the samples in the air and in demineralised water at room temperature. The difference between the two weights in grams was used to determine the volume. Also, the stability and flow were determined. This was done by bringing the samples to the test temperature by immersing them in a water bath for 40 minutes. The guide rods and the inside surfaces of the test heads were thoroughly cleaned. The guide rod was lubricated so that the upper test head could freely slide over it. The specimen from the water bath was placed in the lower segment of the breaking head. The upper segment of the breaking head was placed on the specimen, and the complete assembly was placed in position on the testing machine. The flowmeter was placed in position over the guide rods, and the sleeve was held firmly against the upper segment of the breaking head while the load was applied. The flowmeter was adjusted to zero prior to the start of the test. The load was applied to the specimen at a rate of $50 \mathrm{~mm}$ per minute until the maximum load was reached and the load began to decrease. The maximum load was recorded, and the flowmeter was removed from its position over the guide rod the instant the load began to decrease. The flow value was read and recorded.

\section{RESULTS AND DISCUSSION}

The particle size distribution curves of the aggregates and the mixture of the aggregates for the asphalt concrete are shown in Figure 1. The curve for the mixture of aggregates indicates that it is within the envelope specified in the General Specifications for Roads and Bridges (FGN, 1997). The penetration test results are presented in Table 2. It confirms the grade of the bitumen used in the study.

Table 2: Bitumen penetration test result

\begin{tabular}{|l|l|l|}
\hline & $\mathbf{1}$ & $\mathbf{2}$ \\
\hline Test Temperature $\left({ }^{0} \mathrm{C}\right)$ & 25 & 25 \\
\hline Load $(\mathrm{g})$ & 100 & 100 \\
\hline Penetration $(\mathrm{mm})$ & 65 & 67 \\
\hline Penetration Average $(\mathrm{mm})$ & 66 & \\
\hline
\end{tabular}

The results of the Marshall test, i.e., the stability, flow, density, air voids, voids in the mineral aggregates, and voids filled with bitumen, are shown in Figs. 2 to 7, respectively. Applying the Asphalt Institute Procedure, the bitumen contents were at a maximum stability of 10.3 $\mathrm{kN}$, a maximum density of $2.39 \mathrm{Mg} / \mathrm{m}^{3}$, and air voids of $4 \%$ are $5.0 \%$, $5.5 \%$ and $5.4 \%$ respectively. Therefore, the optimum bitumen content is 5.3 .

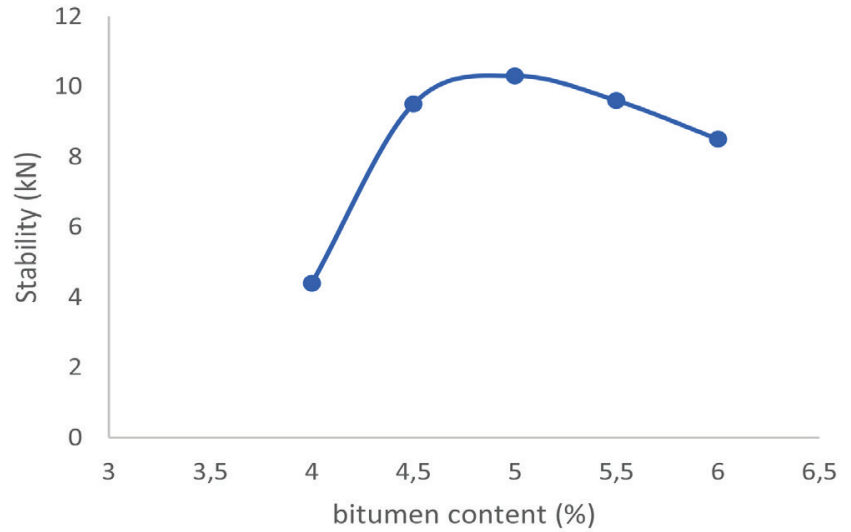

Fig. 2: Stability versus bitumen content for unmodified asphalt concrete

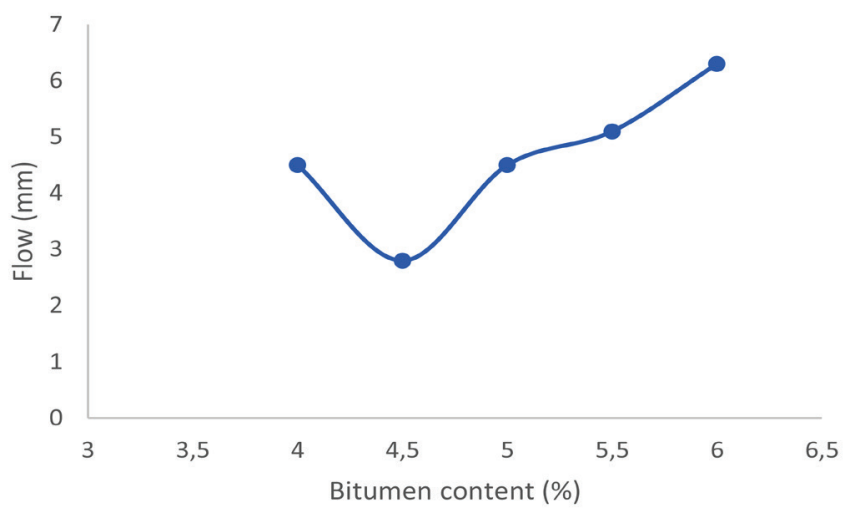

Fig. 3: Flow versus bitumen content for unmodified asphalt concrete

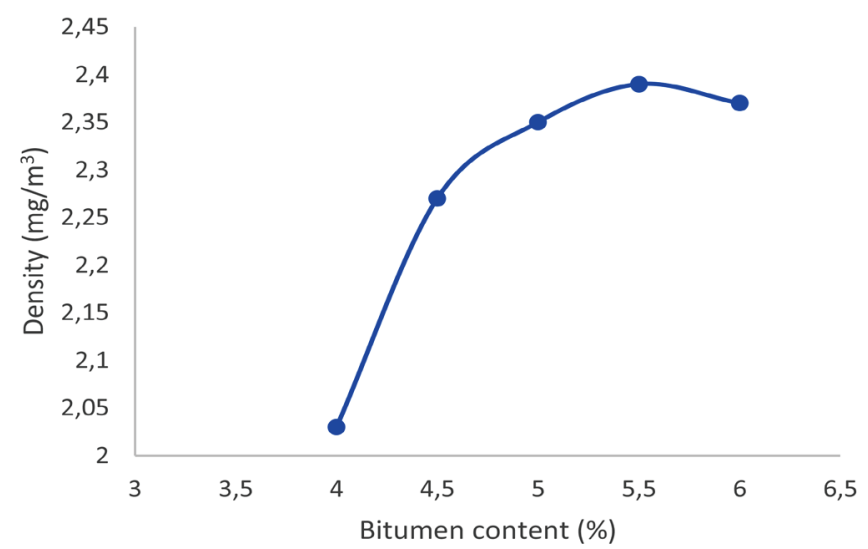

Fig. 4: Density versus bitumen content for unmodified asphalt concrete

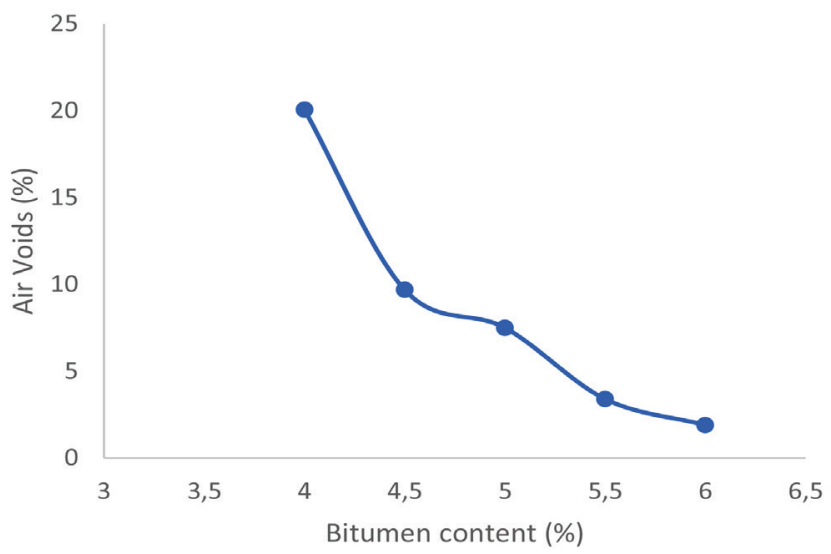

Fig. 5: Air voids versus bitumen content for unmodified asphalt concrete 


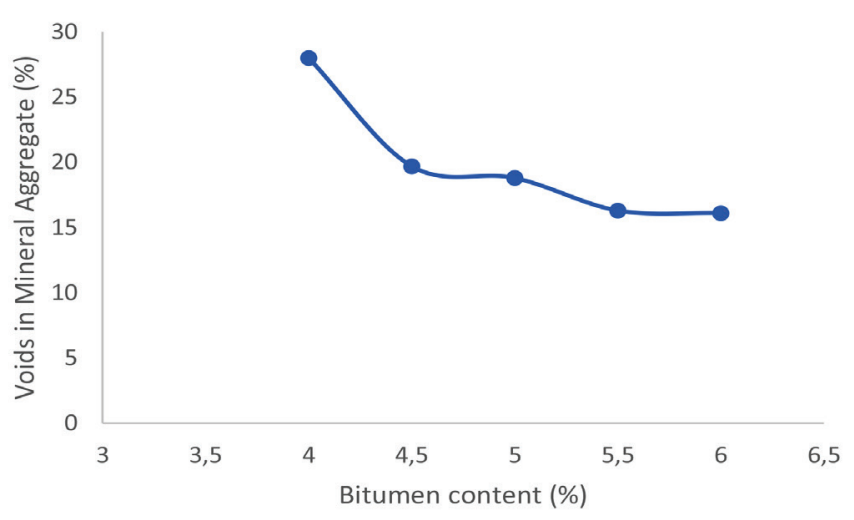

Fig. 6: Voids in mineral aggregate versus bitumen content for unmodified asphalt concrete

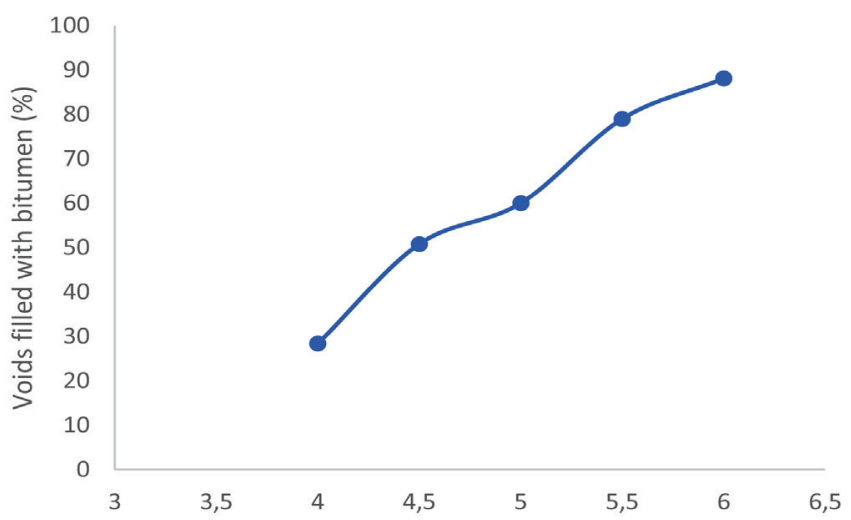

Fig. 7: Voids filled with bitumen versus bitumen content for unmodified asphalt concrete

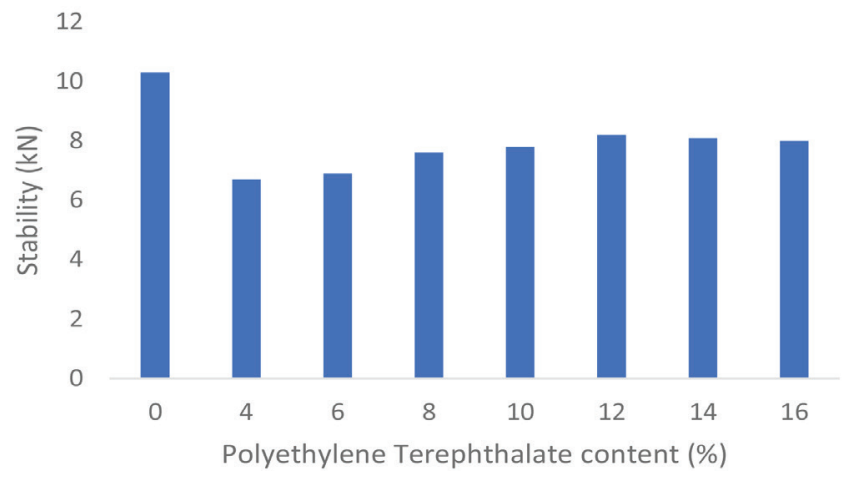

Figure 8: Stability of PET modified asphalt concrete versus the percentage of PET

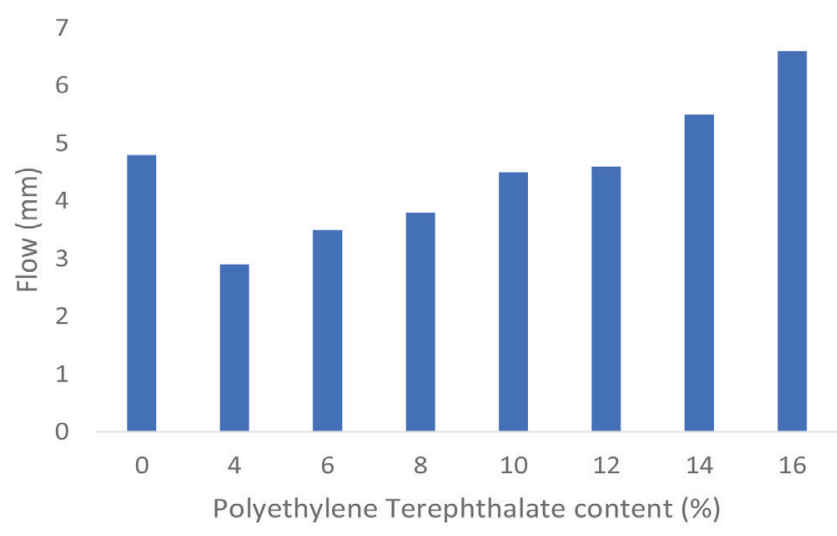

Figure 9: Flow of PET modified asphalt concrete versus the percentage of PET
The graph of stability versus the percentage of PET used in the production of the asphalt concrete is shown in Figure 8. It shows that the introduction of PET into the asphalt concrete reduces its stability. The maximum stability for the PET-modified asphalt concrete was recorded at a $12 \%$ PET content. This gives about a $20.4 \%$ reduction in stability. The reduction in stability agrees with the study of Kotresh et al (2016). The reduction in stability could be attributed to the stability of the mixture of the PET and bitumen. However, the stability values of the PET-modified asphalt concrete samples were all greater than $3.5 \mathrm{kN}$, which is the minimum value specified in the General Specifications for Roads and Bridges (FGN, 1997). This implies the PET-modified asphalt concrete can be used for the construction of pavements.

The graph of the flow versus the percentage of PET used in the production of the asphalt concrete is shown in Figure 9. It shows that the addition of PET to the asphalt causes a reduction in the flow value except with the $14 \%$ and $16 \%$ additions. The flow values at $4 \%$, $6 \%, 8 \%, 10 \%, 12 \%$ and $14 \%$ are within the values of the $2 \mathrm{~mm}$ to 6 $\mathrm{mm}$ specified in the General Specifications for Roads and Bridges (FGN, 1997). The reduction in the flow values could be attributed to the increased stiffness of the PET-modified asphalt, which will in turn improve its permanent deformation resistance. Figure 10 shows the density versus the percentage of PET used in the production of asphalt concrete. The density of the PET-modified asphalt concrete increases with the increasing PET content; the values are lower that the unmodified asphalt concrete. This could be attributed to the lower specific gravity of the PET.

The graph of the voids in the total mix of the asphalt concrete with and without the PET waste is shown in Figure 11. The results show that the air voids increase with the addition of 4 to $12 \%$ PET, while the air voids decrease for the 14 and $16 \%$ PET. The increase in air voids is attributed to the stability of the mixture of bitumen and PET. This also affects the relative ease with which the mixture can be compacted and, consequently, the level of compaction achieved. This is reflected in the results of the density of the PET-modified mixture, which was found to be lower than that of the conventional asphalt concrete except for the samples containing 14\% and 16\% PET, which have a density close to that of conventional asphalt concrete. Figure 12 shows the graph of the voids in the mineral aggregates (VMA) of the asphalt concrete with and without PET. Generally, the VMA of the PET-modified asphalt was greater than that of the unmodified asphalt, except for the samples containing $12 \%$ PET, which has the same value, and 14 and $16 \%$, which are lower. The voids filled with bitumen (VFB) versus the percentage of PET for the unmodified and PET-modified asphalt concrete is shown in Figure 13. The VFB values for the PET-modified asphalt concrete increases with the increasing PET and are lower than the value recorded for the unmodified

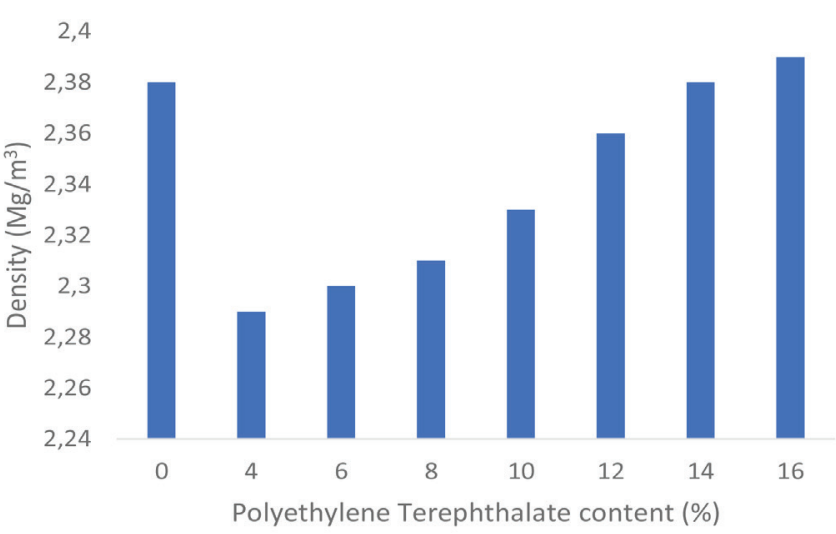

Fig. 10: Density of PET modified asphalt concrete versus the percentage of PET 


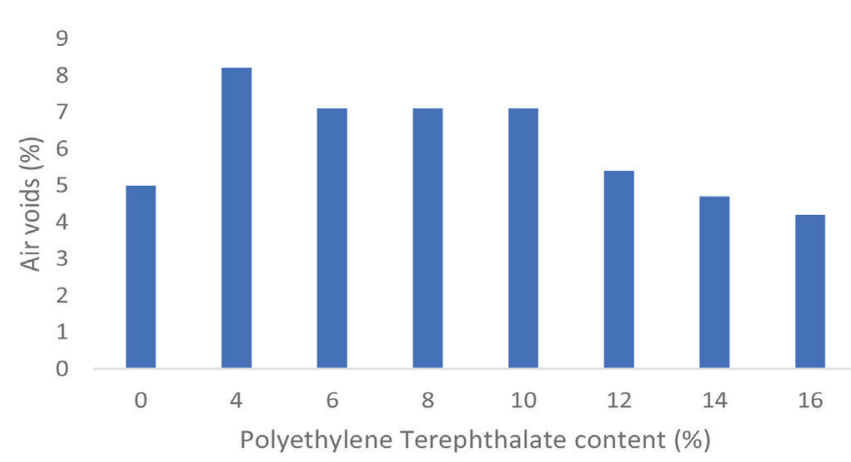

Fig. 11: Air voids of PET modified asphalt versus against the percentage of PET

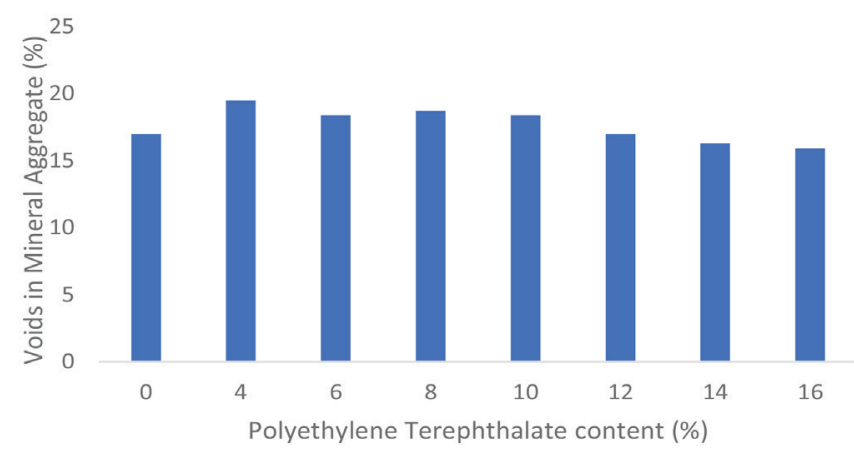

Fig. 12: Voids in mineral aggregate of PET modified asphalt concrete versus the percentage of PET

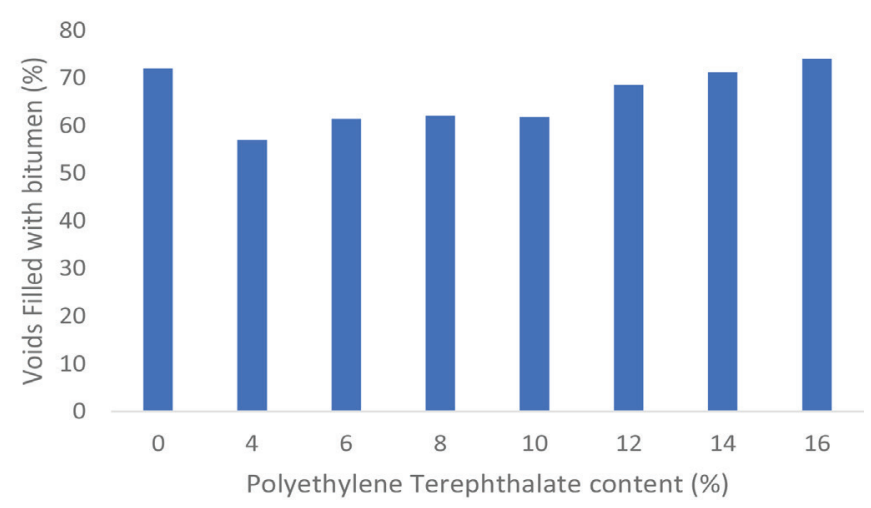

Fig. 13: Voids filled with bitumen of PET modified asphalt concrete versus the percentage of PET asphalt concrete, except for the one with $16 \%$ PET, which is slightly greater than the unmodified asphalt concrete. Generally, despite the concern about the stability of the PET-bitumen mixture, PET could successfully be used to modify asphalt concrete.

\section{CONCLUSIONS}

The study investigates the use of polyethylene terephthalate (PET) in the form of waste bottled-water containers as a modifier for asphalt concrete. The study was necessitated because of the high volume of this waste being generated daily, which makes it imperative that it should be safely disposed of. It was found that the introduction of PET causes a reduction in the stability of the asphalt concrete and it reduces flow. This implies that the introduction of PET could improve the permanent deformation resistance of asphalt, while there is concern about the reduction in fatigue resistance. Generally, the study finds that PET can be successfully used to modify asphalt concrete. However, further tests such as the indirect tensile stiffness modulus, indirect tensile fatigue test or four-point bending test, repeated load axial test, etc., will be required to ascertain the properties of the waste PET-modified asphalt concrete. 


\section{REFERENCES}

Abdul Rahman W.M.N. - Abdul Wahab F.A. (2012). Green Pavement Using Recycled Polyethylene Terephthalate (PET) as Partial Fine Aggregate Replacement in Modified Asphalt. Procedia Engineering, 53:124-128

Abdul Rahman W.M.W - Omardin M.A. (2016). Characterisation of Recycled Polyethylene Terephthalate as Partial Fine Aggregate Replacement Properties and Behaviour of Asphalt Mixtures for Road Pavements. ARPN Journal of Engineering and Applied Sciences, 11(6): 3755-3758.

Ahmadinia E. - Zargar M., Karim M. R - Abdelaziz M. - Shafigh P. (2011). Using Waste Plastic Bottles as Additive for Stone Mastic Asphalt. Materials and Design 32: 4844-4849

Airey G. (1997): Rheological Characteristics of Polymer Modified and Aged Bitumens. PhD Thesis submitted to University of Nottingham.

Appiaha J.K. - Berko-Boatenga V. N. - Tagborb T. A. (2017). Use of waste plastic materials for road construction in Ghana. Case Studies in Construction Materials, 6:1-7

Awaeed K. M. - Fahad B. M. - Rasool D. A. (2012). Utilization of Waste Plastic Water Bottle as a Modifier for Asphalt Mixture Properties. Journal of Engineering and Development, 20(2): 89108.

Awwad M. T. - Shbeeb L. (2007). The Use of Polyethylene in Hot Asphalt Mixtures. American Journal of Applied Sciences 4 (6): 390-396

BSI (2012). Tests for Geometrical Properties of Aggregates: Determination of Particle Size Distribution (Sieving Method). British Standard Institution, London, UK (BS EN 933-1:2012).

BSI (2015). Bitumen and Bituminous Binders: Determination of Needle Penetration. British Standard Institution, London, UK (BS EN 1426:2015; BS 2000-49:2015).

FGN (1997). Government of the Federal Republic of Nigeria, General Specifications (Roads and Bridges), Volume II, 1997.

Gawande A. - Zamre G. S. - Renge V. C. - Bharsakale G. R. - Tayde S. (2012). Utilization of Waste Plastic in Asphalting of Roads. Sci. Revs. Chem. Commun. 2(2):147-157.

Hassan A. - Ganjidoust H. - Maghanaki, A.A. (2005). Use of Plastic Waste (Polyethylene Terephthalate) in Asphalt Concrete Mixture as Aggregate Replacement. Journal. Waste Management and Research, 23(4):322-327.

Jabarin A. S. (1996). Polyethylene terephthalate chemistry and preparation, The Polymeric Materials Encyclopedia, CRC Press.
Kotresh K. M. - Y. B. Kebede - Bhavya R. - Vageesh, H. P. (2016). A Study on Use of Plastic Wastes in Road Pavement Construction. International Journal of Innovative Research in Science, Engineering and Technology. 5(4): 5955-5961.

Lewandowski L. H. (1994). Polymer modification of paving asphalt binders. Rubber Chemistry and Technology, 447-480.

Lytle, C. L. G. (2011). When mermaids cry: The great plastic tide. Ecological and Human Health Impacts: http://www.unspecial. org/2014/06/when-the-mermaids-cry-the-great-plastic-tide.

Moghaddam T.B. - Karim M. R. - Soltani M. (2013). Utilization of Waste Plastic Bottles in Asphalt Mixture. Journal of Engineering Science and Technology. 8(3):264 - 271

Rahman M. N. - Ahmeduzzaman M. - Sobhan M. A. - Ahmed T. U. (2013). Performance Evaluation of Waste Polyethylene and PVC on Hot Asphalt Mixtures. American Journal of Civil Engineering and Architecture, 1(5):97-102.

Sabina, Khan T. A - Sangita, Sharma D. K. - Sharma B. M. (2009). Performance evaluation of waste plastic/polymers modified bituminous concrete mixes. Journal of Scientific and Industrial Research, 68:975-979.

Shiva P. K. - Manjunath K. R. - Prasad K. V. R (2012). Study on Marshall Stability Properties of BC Mix Used in Road Construction by Adding Waste Plastic Bottles. IOSR Journal of Mechanical and Civil Engineering, 2(2):12-23.

Sui Y. - Chen Z. (2011). Application and performance of polyethylene modifying additive in asphalt mixture. Proceedings of International Conference on Transportation Engineering (ICTE), 1915-1919.

Sulyman M. - Sienkiewicz M. - Haponiuk J. (2014). Asphalt Pavement Material Improvement: A Review. International Journal of Environmental Science and Development, 5(5): 444-454.

Sulyman M. - Haponiuk J. - Formela K. (2016). Utilization of Recycled Polyethylene Terephthalate (PET) in Engineering Materials: A Review. International Journal of Environmental Science and Development, 7(2):100-108.

Vasudevan R. - Nigam S. K. - Velkennedy R. - Sekar A. R. C. - Sundarakannan B. (2010). Utilization of waste polymers for flexible pavement and easy disposal of waste polymers, Proceedings of International Conference on Sustainable Solid Waste Management. Chennai, India, 105-111. 